\title{
ROBERT SKIDELSKY. LA BIOGRAFÍA \\ DE UN GRAN ECONOMISTA: \\ JOHN MAYNARD KEYNES
}

ANTONIO TORRERO MAÑAS

Universidad de Alcalá

\section{UNA GRAN BIOGRAFÍA}

La primera biografía de Keynes la publicó Harrod (1951), cinco años después de su muerte; el autor de la segunda fue Moggridge (1976), gran conocedor de la obra de Keynes y responsable de la mayor parte de los Collected Writings (CW) ${ }^{1}$, obra que completaría en 1992 con la magnífica Maynard Keynes. An economist' biograpby. Otros libros biográficos con planteamientos menos generales son los de Hession (1984), Mini (1994) y Felix (1999). Los artículos biográficos son muy numerosos; los más importantes están recogidos en el volumen I de los Critical Assessments, editados por Cunnigham Wood (1983), y en la primera parte del libro de M. Keynes (1975).

De manera que la vida del economista más influyente de la historia ha recibido una atención notable. Me atrevo a señalar, sin embargo, que los tres volúmenes de Skidelsky constituyen la gran biografía del genio de Cambridge ${ }^{2}$. Lo es por su conocimiento del biografiado, por la amplitud con la que describe su personalidad, insertándola en el cañamazo de su

1 Treinta tomos publicados por la Royal Economic Society y editados por The Macmillan Press LTD., que aparecen a partir de 1971 hasta 1989. Todas las citas de Keynes corresponden a esta edición, indicándose el año de la primera publicación, el volumen de los Collected Writings y la página correspondiente.

${ }^{2}$ Los tres tomos tienen como título común Jobn Maynard Keynes, y los subtítulos: 1) «Hopes Betrayed 1883-1920» (1983); 2) «The Economist as Saviour 1920-1937» (1992), y 3) «Fighting for Britain 1937-1946» (2000). En este trabajo se utilizarán para las citas las iniciales de los subtítulos, esto es: $\mathrm{HB}, \mathrm{ES}$ y FB. 
época, y por no eludir ninguno de los temas que considera relevantes aunque sean espinosos y delicados. Skidelsky es un historiador que ha estudiado economía y no rehúye pronunciarse respecto al sentido y alcance de la obra económica de Keynes, ni elude los juicios sobre su interpretación posterior. Aunque su propósito inicial fuera «... estudiar la vida de Keynes, lo cual es distinto al estudio de la economía keynesiana o de Keynes como economista», la realización de su obra lo lleva a ampliar esa perspectiva inicial; incluso me atrevo a asegurar que el seguimiento del proceso de creación intelectual de Keynes constituye uno de los puntos más brillantes de la biografía. La trilogía es la aportación central de Skidelsky como investigador. Con motivo de la publicación del tercer volumen rememora que su contrato con la editorial data de 1970, con el compromiso de escribir un solo volumen, a entregar antes de finalizar 1972, y exponía entonces que: «Un biógrafo de Keynes tiene que ser capaz de explicar la lógica de su pensamiento, y tener en cuenta siempre por qué Keynes pensaba de esa forma, y por qué se manifestaba de la forma en que lo hacía en cada momento concreto».

Skidelsky ha empleado más de veinte años de trabajo en esta obra y ha quedado progresivamente subyugado por la personalidad de Keynes, al punto de adquirir la casa de campo de éste, en Tilton. Confiesa que le hubiera encantado conocerle, si Keynes hubiera demostrado disposición, puesto que tiene muy en cuenta el carácter difícil y rudo que podía mostrar con algunas personas y también la afabilidad y comprensión de que hacía gala con los que apreciaba. Skidelsky se muestra comprensivo, pero también crítico, con la biografía de Harrod. Es éste el trabajo de un discípulo respetuoso, realizado y publicado ante la observación vigilante de la familia y amigos de Keynes, con una misión ejemplarizante. Con este planteamiento omite la orientación sexual de Keynes, trivializa su relación con el dinero y las finanzas, y diseña, en definitiva, una imagen impoluta del brillante economista con una vida ejemplar dedicada al servicio público. Como resumiría K. Martin, editor del New Statement: «Ésta es la biografía de Lord Keynes, alguien debe escribir la vida de Maynard». Ese alguien ha sido Skidelsky.

Dado que existen muchas y muy diferentes interpretaciones de la obra de Keynes, conviene situar la posición de Skidelsky. En los años ochenta, un conjunto de investigadores: O'Donnell, Carabelli, Bateman, Moggridge y el propio Skidelsky, propusieron una nueva interpretación de la obra de Keynes. Hasta entonces, la lectura de sus aportaciones económicas se consideraban sin ponerlas en relación con otras actividades extraeconómicas 
o con publicaciones no específicamente económicas. Especial trascendencia tendría la nula consideración del Treatise on Probability ${ }^{3}$, publicado en 1921 , pero en el que vuelca su esfuerzo en los años de formación (1906-1914; entre los veintitrés y los treinta y un años). La nueva aproximación considera esencial ese libro para comprender los fundamentos filosóficos de Keynes y su forma de abordar los problemas económicos; de manera especial su contenido ayuda a iluminar pasajes que antes se consideraban sin interés. Como señala McCann (1998): «El Estado de las Expectativas a Largo Plazo», capítulo 12 de la Teoria General, adquiere un significado más profundo en el contexto del Treatise que si se lee sólo en el contexto de la modelización empírica macroeconómica». La apreciación de Hicks (1969) del capítulo 12 de la Teoría General es muy diferente. Rechaza que las expectativas tengan autonomía y se configuren al margen de las variables económicas. «Quizá sea en este famoso (pero ahora creo que bastante perverso) capítulo sobre "las expectativas a largo plazo" donde radique la raíz del problema». Si unos lo consideran una aportación fundamental, para otros, como Hicks, es un elemento perturbador que interfiere con su ordenada interpretación de la Teoría General. No es extraño que Skidelsky resalte la lejanía de Hicks, que si bien no jugó papel alguno en la génesis de la Teoría General, llegaría a ser el intérprete más influyente y el representante más autorizado de la Revolución Keynesiana.

\section{UN ECONOMISTA MUY ESPECIAL}

Cuando surge un innovador, un genio que revoluciona una ciencia, suele plantearse como principal interrogante qué vías hicieron posible que cuajara la personalidad creativa. Esto ha sucedido con Keynes, y uno de los puntos fuertes de la biografía de Skidelsky es el seguimiento de la formación de Keynes, sus reacciones ante las vicisitudes sociales y económicas que pusieron a su intelecto en tensión para intentar comprenderlas, explicarlas y ofrecer las opciones más favorables para resolver los problemas.

${ }^{3} \mathrm{La}$ singularidad en la apreciación del Treatise on Probability explica que esté fuera del orden cronológico en los CW, en los cuales debería ocupar el vol. III y no el VIII. Según Moggridge (1992, pp. 143 y 144), en un principio, la colección se limitaría a los escritos económicos publicados más importantes, y el Treatise on Probability no entraba en esta consideración. En contraste con el Treatise on Money o la Teoría General, el Treatise on Probability no iba acompañado de la correspondencia en torno a la publicación, aunque es el único en el que figura una introducción de $\mathrm{R}$. Braithwate, seguramente para encuadrar su contenido para los economistas. 
La investigación de Skidelsky tiene éxito, entre otras razones, porque su análisis abarca las distintas facetas de la rica personalidad de Keynes.

Keynes era sobre todo un economista. Su mujer decía que era más que un economista, y es cierto que su personalidad y su capacidad de influir traspasaban las fronteras que se consideran normales en la profesión, pero estoy de acuerdo con Skidelsky en que el objetivo de Keynes, en su madurez, no fue otro que el de llegar a ser un gran economista tal y como él entendía la misión de esta profesión. A lo largo de su biografía, Skicelsky analiza las actividades profesionales de Keynes y los diferentes ambientes en los que transcurrió su vida. Fue funcionario público al comienzo de su carrera, durante un corto espacio de tiempo, aunque en las dos guerras mundiales prestó sus servicios al Gobierno. En la primera, contratado de manera formal y retribuida; en la segunda, su papel fue muy importante aunque sin cargo definido ni remuneración. En sus inicios, enseñó economía en Cambridge, concentrando su atención desde el principio en temas monetarios y financieros. Después de la primera guerra redujo su dedicación académica, que nunca abandonó del todo, trasladando su residencia a Londres, desarrollando una intensa vida de relación en los círculos influyentes de la Administración y de la City, y dedicando atención progresiva a la actividad periodística tanto como medio de vida como para difundir sus ideas y defender sus propuestas. Fue inversor y especulador por cuenta propia y de sus amigos, y gestor de patrimonios institucionales, destacando la presidencia de la National Mutual Life Insurance entre 1921 y 1938, así como el cargo de administrador (bursar) de su Universidad entre 1919 y 1946. Formaba parte del grupo artístico e intelectual de Bloomsbury. En su madurez, tuvo experiencia como propietario de una explotación agrícola, y la cercanía al mundo rural se aprecia con claridad en sus trabajos de la década de los años treinta. Esta variedad de actividades, experiencias y ambientes es destacada reiteradamente por Skidelsky, apuntando con acierto que la diversidad de perspectivas enriquecía sus análisis y estimulaba su imaginación creadora: «Nunca ha habido un economista como él: alguno que combinara tantas cualidades a tan alto nivel facilitando que todas fertilizaran su pensamiento. Fue un economista con una mente abierta, de curiosidad insaciable; un matemático que podía deslumbrar a la gente con las ideas menos matemáticas; un lógico que aceptaba la lógica del arte; un arquitecto que dejó monumentos en piedras y en palabras; un teórico puro, un teórico aplicado y un servidor público, todo al tiempo; un académico familiarizado con la City». Está claro, pues, y así lo resalta Skidelsky, la importancia que tiene para comprender la 
génesis y el contenido de la obra de Keynes la diversidad de su experiencia profesional, la variedad de ambientes en los que se desenvolvía su vida. En relación a este asunto, me parece importante destacar el reflejo de esta diversidad sobre su poder de convicción, algo extremadamente importante para Keynes. Ese poder de convicción ${ }^{4}$ procede en ocasiones de su capacidad de desenvolverse en terrenos que el interlocutor no conocía, de modo que el debate quedaba marcado por el peso de su conocimiento en aspectos con los que la otra parte no estaba familiarizado. Esta circunstancia se advierte en el respeto de otros economistas hacia los argumentos de Keynes, procedentes de campos para ellos desconocidos y que suponían que éste dominaba a la perfección.

En esa línea, a Marshall, por ejemplo, le impresiona la familiaridad de Keynes con los ambientes gubernamentales ${ }^{5}$. Su superior en la Oficina de la India alaba el mérito del trabajo de Keynes, destacando que une a sus conocimientos de los asuntos indios el rigor de un economista profesional ${ }^{6}$. Con Hawtrey, Keynes apelará a su conocimiento directo de las compañías de seguros para convencerle de los mecanismos que determinan las inversiones ${ }^{7}$, o dejará caer el peso de su conocimiento como especulador en materias primas para argumentar que el tipo de interés tiene una influencia menor que las expectativas de variación de los precios para que los comerciantes decidan el almacenamiento ${ }^{8}$. A los mutualistas de la National Mutual les deslumbra con sus conocimientos de economía ${ }^{9}$. Es fácil comprender, por último, el asombro y admiración que despertarían en el ambiente académico del King's College los espléndidos resultados obtenidos por las inversiones cuando Keynes se ocupó de la administración de los fondos de la Universidad.

${ }^{4}$ En mis opiniones personales he utilizado ideas expuestas en Torrero (1993 y 1998).

5 «... Usted sabe mucha más economía que ningún hombre de Estado; y conoce mucho más las dificultades de Whitehall... que ningún economista profesional». Carta de A. Marshall a J. M. Keynes, el 13 de junio de 1917 (XVI, p. 223).

${ }^{6}$ Carta de L. Abrahams a J. M. Keynes, el 19 de abril de 1911 (XV, p. 66).

${ }^{7}$ Carta de J. M. Keynes a R. G. Hawtrey, el 30 de octubre de 1935 (XIII, p. 594).

8 «No hablo sobre este asunto como un teórico sino como alguien con un conocimiento práctico del mercado de materias primas y de sus mecanismos. Honestamente, sé mucho de esto apoyado por mi experiencia y estoy completamente seguro de que Vd. está equivocado». Carta de J. M. Keynes a R. G. Hawtrey, el 6 de enero de 1936 (XIII, p. 627).

${ }^{9}$ Los discursos de Keynes como presidente de la empresa en la Junta General Anual constituyen un material espléndido para comprobar"su capacidad dialéctica y la evolución de su pensamiento como economista e inversor. A mi juicio, este material ha sido infrautilizado por Skidelsky. Está recogido en XIII, pp. 114-238. En Torrero (1998, cap. 6) se revisan estos textos. 
La preparación para desarrollar su carrera como economista fue tardía y parca. Cuando tenía veintidós años, empezó a leer a Marshall y aún no había decidido ser economista, aunque había mostrado con claridad su deseo de ganar dinero. A A. Smith lo leyó cuando tenía veintisiete años. En una carta a Strachey, el auténtico líder intelectual del grupo de Bloomsbury y su rival sentimental, a finales de 1905 , se manifiesta al respecto: «Encuentro la economía crecientemente satisfactoria y creo que soy bastante bueno en eso. Quiero administrar un ferrocarril u organizar un trust o al menos engañar al público inversor». El tono desenfadado de la misiva no tiene mayor importancia y es preciso encuadrarlo en la relación de Keynes con Strachey, marcada por una disputa constante por sobresalir en irreverencia. Esta carta es reproducida por Harrod que elimina el molesto final del párrafo. Skidelsky pone este incidente como ejemplo del deseo de Harrod de maquillar u ocultar todo lo que pudiera turbar la inmaculada imagen que quería transmitir de Keynes.

Los intentos de Marshall por encaminar a su admirado discípulo hacia la economía fueron constantes, pero en sus exámenes para entrar en el sector público, en 1906, entre las calificaciones más bajas está la que obtiene en economía. Keynes no consiguió ningún grado académico en economía; empezó a tomar en serio su estudio cuando inició su actividad de profesor en Cambridge después de abandonar su puesto de funcionario en la Oficina de la India, ante la indignación de su padre. Había estudiado, pues, poca economía cuando comenzó a explicarla. En su aprendizaje sería fundamental su trabajo como editor del Economic Joumal, labor que inició en 1911 y mantendría con dedicación intensa hasta 1945. Skidelsky señala que, a la altura de 1920, cuando Keynes tenía treinta y siete años, era conocido por ser el autor de The Economic Consequences of the Peace, pero no había hecho ninguna contribución destacada en el campo de la economía.

La relación de Keynes con el dinero, con los asuntos monetarios y financieros, juega un papel importante en su vida y en su aportación como economista. En primer lugar, la consecución de un patrimonio le dio libertad para dirigir su vida profesional; en segundo término, la actividad que desarrolló en la City para conseguir ese patrimonio le proporcionó una experiencia profesional muy poco frecuente en personas con actividad académica, y le dotaron de un instinto, de una sensibilidad especial para obser- 
var la economía desde el ángulo financiero ${ }^{10}$. Skidelsky pone de relieve esta visión financiera que es preciso situar, no obstante, en una persona con un amplio espectro de inquietudes.

La faceta financiera que se advierte claramente antes de la Primera Guerra, se intensificaría en el período de entreguerras. Skidelsky señala muy expresivamente que Falk ${ }^{11}$ era quizá quien mejor conoció a Keynes entre 1920 y 1937, y resalta el enfoque monetario como piedra angular de su análisis, constantemente inspirado en la incidencia del dinero sobre las variables reales. De hecho, el destacar el papel del dinero en la materialización de la riqueza y como medida de la desconfianza hacia el futuro constituye una de sus principales aportaciones. Apunta su biógrafo que la línea hacia la Teoría General está ligada a la City tanto como a la teoría monetaria de Cambridge o al multiplicador de Kahn. Su dominio de las finanzas era un factor que lo diferenciaba de otros economistas, y su teoría de la preferencia por la liquidez está inspirada en su actividad especuladora.

En 1931, en sus declaraciones ante el Comité Macmillan, que constituye uno de los momentos claves en la reorientación del pensamiento de Keynes, al punto de que Skidelsky entiende que se inicia entonces la revolución keynesiana, el biógrafo imagina cómo se hubiera manifestado Keynes respecto a la decisión de invertir: «Creo que soy el primer economista que ha puesto énfasis en el motivo especulación en las decisiones de inversión, que surge de la incertidumbre respecto al precio de los valores en el futuro. Dada esta incertidumbre, la inversión es sobre todo un asunto de impulsos (animal spirits). Tiene poco o nada que ver directamente con las decisiones de la comunidad de consumir o ahorrar. Sé de lo que estoy hablando porque he estado practicando este juego los últimos diez años». Keynes estaba, pues, familiarizado con las finanzas y ello constituye una característica distintiva de su personalidad, pero es conveniente precisar el alcance de los conocimientos financieros de Keynes, ya que el campo financiero integra especialidades y conocimientos muy distintos, y la especialización en un área determinada responde, aparte de las oportunidades y circunstancias de una carrera profesional, al talante personal que se marca en la elección.

Un experto financiero que trabaja en banca comercial tiene poco en común con otro que lo hace en seguros, en una firma de bolsa, en un

${ }^{10}$ Esta sensibilidad para elegir los temas objetơ de atención y para utilizar un enfoque financiero en su análisis, ha sido la idea fundamental que ha inspirado mi libro sobre Keynes (Torrero, 1998).

1 Falk fue el introductor de Keynes en las actividades financieras de la City. 
banco de inversión, en el Banco de Inglaterra o en el Tesoro. De Keynes podemos decir que trabajaba en seguros y sociedades de inversión, y no en puestos estrictamente ejecutivos, concentrando su atención en la inversión de la cartera de valores. Así, los conocimientos e intereses de Keynes se corresponden con la formación de lo que es en la actualidad un analista financiero, esto es, un experto que analiza datos y mercados para detectar oportunidades y evaluar posibilidades de inversión, pero con una excelente formación general y, particularmente, en economía. Lo anterior explica la escasa preocupación de Keynes hacia aspectos institucionales o empresariales de las finanzas. Las referencias a la estructura del sistema bancario, por ejemplo, son ocasionales, y los defectos que encuentra los achaca a la falta de preparación de los banqueros, pero aceptando la organización existente, ya que rara vez cuestionaba la estructura vigente, y en este sentido era de un conservadurismo notable. Entiendo que hacer referencia a su familiaridad con las finanzas añade poco si no se especifica cuál era su preparación y el objeto de su atención. Hacia esta especialización le condujo, sin duda, su deseo de ganar dinero, lo cual sólo era factible, si se aspiraba a un determinado nivel de vida, implicándose en el mundo de los negocios, y también para intentar conservar el mayor grado posible de independencia personal que le permitiera intervenir en la vida pública desde una posición altruista (presuposiciones de Harvey Road), procurando el bienestar general.

Un aspecto relevante para comprender la personalidad y la génesis de la obra es el tono de rebeldía de Keynes. Las matizaciones de Skidelsky al respecto son clarificadoras. Es cierto que en los aspectos culturales, artísticos y morales, Keynes se sitúa en el vanguardista grupo de Bloomsbury, que se revela contra el puritanismo victoriano. Sin embargo, en cuanto a la economía, el punto de partida de Keynes es la aceptación de los postulados básicos del pensamiento conservador inglés. Era un partidario decidido del libre comercio. En el Tract on Monetary Reform (1923), se encuentra uno de los alegatos más fervientes contra la inflación y una interpretación muy positiva del papel de los especuladores, aunque también una cerrada defensa de la autonomía del Reino Unido para realizar una política propia, aspecto fundamental que mantendría toda su vida.

Si en la evolución normal de la personalidad se considera primero la rebeldía juvenil, seguida por una mayor aceptación de las convicciones predominantes en la madurez, el pensamiento económico de Keynes no responde a ese patrón. Keynes parte de la aceptación de los principios básicos, teñidos de rebeldía en aspectos concretos y menores (críticas a 
la actuación de los banqueros en 1914), para ir radicalizando sus posiciones, y revisando críticamente el pensamiento tradicional en el período de entreguerras, de máxima fertilidad creadora, hasta llegar a la dureza del ataque a lo que denomina la economía clásica en la Teoría General. A partir de ahí, en la última etapa de su vida, cubierta por el tercer volumen de Skidelsky, se suavizan las aristas críticas, obviando los planteamientos más radicales (la eutanasia del rentista, por ejemplo). y reivindicando el papel de los mecanismos de la economía clásica en la asignación de los recursos. Skidelsky destaca la colaboración de Keynes con el Arzobispo de York en 1942, en el curso de la cual Keynes pone énfasis en el aspecto ético de la economía y en cómo los primeros economistas fueron hombres de iglesia. El biógrafo concluye: «Había recorrido un largo camino desde la firmeza en el ateísmo de su juventud».

En esta trayectoria jugó un papel fundamental la resolución de los problemas prácticos. Keynes se interesa por la teoría cuando ésta no le parece válida para comprender la realidad. Skidelsky sitúa la ruptura con la herencia recibida en 1924 y 1925 cuando se enfrenta al Tesoro y al Banco de Inglaterra con motivo del retorno al patrón oro. Si The Economic consequences of the Peace constituye una rebelión moral, aunque con un análisis extraordinario de la interdependencia económica de Europa, el retorno al patrón oro supone también la rebeldía en economía. A partir de entonces, dos temas serían fundamentales: la dificultad de ajuste de una economía moderna y la imposibilidad de mantener una política de laissez-faire.

El supuesto de que los salarios caerían respondiendo a un alza de los tipos de interés convenció a Keynes de lo erróneo del modelo aceptado por los dirigentes de la economía inglesa. La declaración de Churchill, orientada por el Tesoro: «El retorno al oro no tiene más conexión con los problemas del carbón que la corriente del Golfo», debió de ser un acicate para Keynes, que veía con claridad la incidencia negativa del retorno sobre la estructura productiva. La clave del error residía en la creencia de que si se favorecía la deflación de precios mediante la revaluación del tipo de cambio, ello conllevaría la deflación de costes.

Pero si Keynes se radicaliza en su crítica de la doctrina recibida, se opera la evolución contraria en sus ideas respecto a las finanzas. En el campo financiero parte de una actitud audaz e innovadora que, progresivamente, se torna conservadora hasta finalizar en una posición inversora basada en la correcta selección y mantenimiento a largo plazo de las acciones, criticando, por tanto, los efectos de la especulación y de la liquidez. 
Mi interpretación es que el mejor conocimiento de la realidad de los mercados le hizo ser consciente de sus propias limitaciones como inversor y, al tiempo, le mostró cada vez con mayor nitidez la insuficiencia de la teoría económica aceptada, que no consideraba la compleja realidad de los mercados que él vivía con diaria intensidad.

La extraordinaria capacidad de Keynes para percibir la realidad a través del prisma de las finanzas contrasta, por otra parte, con su escasa sensibilidad respecto a los temas industriales y empresariales. El mundo de la Universidad y de la City tenían escasa relación con la estructura productiva inglesa. Keynes no tenía la inquietud de Marshall para intentar conocer los procesos productivos, ni valoraba como él la importancia de la formación específica para la innovación y la capacidad competitiva. En una charla radiofónica de 1927, Keynes se pronunció claramente en contra de que la Universidad preparara de forma específica para la gestión empresarial. En cuanto a la opinión sobre los empresarios, no se advierte en Keynes el tono apreciativo, romántico y caballeresco de Marshall, y apenas conocía a empresarios industriales. Su biógrafo señala al respecto: «La impresión fundamental de Keynes respecto de los hombres de negocios ingleses era su estupidez y desidia. Creía firmemente en el ciclo de las tres generaciones: el hombre de energía e imaginación que crea la empresa; el hijo que continúa; y el nieto que la quiebra».

Keynes se acerca al conocimiento de dos sectores productivos en la década de los veinte: al minero, que resultaría afectado de forma más directa e inmediata por el retorno al patrón oro con una paridad sobrevalorada, como brillantemente predijo; y al textil, al intervenir en la reorganización de la industria. Skidelsky, con mucho acierto, analiza la aportación de Keynes a The Liberal Industrial Inquiry en 1926 (apenas mencionada por Harrod), destacando la parcialidad del enfoque. «Aparte de las empresas de servicios públicos, ni una sola empresa manufacturera o comercial aparece en la lista de Keynes». El mundo de la empresa, para Keynes, queda reducido a las grandes empresas de servicios públicos, que cuando alcanzan un gran tamaño dejan de comportarse como empresas privadas. En este tipo de corporaciones, que efectivamente realizan la mayor parte de inversión total, el beneficio pasa a un segundo plano, y las remuneraciones de los directivos se conciben más en la línea de funcionarios que como recompensas a la función empresarial o a la asunción del riesgo.

Keynes tenía un contacto muy escaso con el mundo empresarial, pero el poco que tenía, más que orientarlo dificultaba su percepción de los problemas ingleses. El carbón y el textil del algodón eran industrias maduras 
con una problemática empresarial completamente distinta a la de los nuevos sectores que ofrecían posibilidades extraordinarias (químico, eléctrico, comunicaciones) y en los que la participación del Reino Unido era reducida porque carecía del impulso empresarial suficiente. El tono despectivo hacia los empresarios, la escasa importancia que asigna a los beneficios empresariales en las decisiones de inversión, la brillante ocurrencia de las tres generaciones, la culpabilización, en fin, a la institución de la herencia, no contestaban a la cuestión crucial de por qué en Alemania, y sobre todo en los Estados Unidos, no sucedía eso.

Keynes acertó con las consecuencias que se derivarían para el Reino Unido del retorno al patrón oro. Sus consideraciones sobre esta cuestión son extraordinarias y de un gran mérito analítico, pero, como advierte Skidelsky, sobrevaloró la importancia de este hecho para explicar el declive británico. Las soluciones que propone en The Liberal Industrial Inquiry, aunque con observaciones agudas, se limitan a diseños intervencionistas para organizar las grandes empresas existentes sin detenerse a analizar las razones del escaso pulso empresarial inglés en general y, particularmente, el reducido protagonismo en los nuevos sectores. Ésta es una limitación muy importante de Keynes para comprender precisamente lo que más le preocupaba en la segunda mitad de la década de los veinte: la atonía inglesa en un mundo no sólo en expansión, sino que estaba experimentando un intenso crecimiento, que cercenaría la Gran Depresión. En repetidas ocasiones argumenta que no hay grandes diferencias en la eficiencia con la que los países industriales podían fabricar la gran mayoría de los artículos manufacturados, lo cual abría la puerta a la tentación proteccionista. El biógrafo destaca el deslizamiento en esta dirección que se advierte, con particular intensidad, en su ensayo National Self-Sufficiency ${ }^{12}$. Como señala Skidelsky: «Keynes plantea con rotundidad que la libertad de comercio, en combinación con la movilidad internacional del capital, probablemente provocó la guerra antes que salvaguardar la paz».

Estas convicciones de Keynes ayudan a comprender llamativos vacíos en la Teoría General. El biógrafo señala, con agudeza, que en ese libro los «factores psicológicos ocupan el papel dominante: la topografía industrial se considera dada y no es objeto de análisis». Hasta un economista que puede considerarse académico puro, como Pigou, reprocharía a Keynes, en la recensión de la Teoría General, con toda razón, la escasa importancia que asignaba al progreso técnico en unos años en los que se advertían

${ }_{12}$ The New Stateman and Nation, 8 y 15 de julio de 1933 (XXI, pp. 233-246). 
las posibilidades expansivas de los nuevos avances que apuntaban oportunidades extraordinarias.

\section{EL REMONTE DEL VUELO. LA TEORÍA GENERAL}

Los dos años que transcurren entre el desplome de la bolsa de Nueva York, en octubre de 1929, y el abandono del patrón oro por el Reino Unido, en septiembre de 1931, fueron para Keynes de una actividad frenética ${ }^{13}$. Skidelsky hace un seguimiento detallado de este período clave en la evolución del pensamiento de Keynes, y presta especial atención a las declaraciones ante el Comité Macmillan a las cuales limito este breve comentario.

Este Comité fue establecido para investigar las relaciones entre la banca y la industria como consecuencia de la inquietud hacia la escasa preocupación que algunos advertían en la banca respecto a la financiación empresarial. Ésta no es una cuestión que preocupara demasiado a Keynes, lo cual es significativo considerando su especialización financiera. Keynes interviene, y de una forma intensa, cuando se aborda el objeto central de su preocupación, que era el bajo tono de la economía británica a la cual se había impuesto un peso con el tipo de interés para defender la paridad de vuelta al patrón oro, que pesaba como una losa. Su bagaje era el del Treatise on Money que publicaría en 1930, y su biógrafo subraya que Keynes tuvo la oportunidad de contrastar en el Comité sus ideas con personas experimentadas en la gestión de los asuntos públicos: «La Teoría General fue, en parte, una respuesta a las objeciones del Banco y del Tesoro a sus propuestas».

En el período de sesiones del Comité se produjo un acontecimiento de gran trascendencia: el comienzo de lo que sería la Gran Depresión. Este evento altera la orientación de Keynes y del Comité, que pasan la situación internacional al centro de la escena. La Gran Depresión le permite

${ }^{13}$ En este período destacan las siguientes actividades: 1) como componente del Comité Macmillan tuvo un protagonismo destacado en las numerosas reuniones que tiene lugar entre el 21 de noviembre de 1929 y 29 de mayo de 1931; 2) preside el Comité de Economistas que desarrolla su actividad los meses de septiembre y octubre de $1930 ; 3$ ) en octubre de 1930 publica el Treatise on Money; 4) el 30 de mayo de 1931 emprende su segundo viaje a los Estados Unidos (el primero lo realizó en 1917) donde permanecería hasta el 13 de julio; 5) inmediatamente después del abandono de la libra del patrón oro el 21 de septiembre de 1931 prepara la publicación de Essays in Persuasion que aparecería en noviembre del mismo año. 
a Keynes alzar el vuelo y dedicar su inteligencia y sensibilidad a descifrar un enigma. Samuelson diría al respecto que la Gran Depresión le proporcionó un desafío, un drama, una confirmación experimental. La Gran Depresión conectaba con las capacidades de Keynes. En efecto, se trataba, en primer lugar, de un fenómeno de alcance mundial aunque tuviera como epicentro los Estados Unidos, y, en segundo término, el origen del cataclismo y sus efectos difusores eran de naturaleza financiera. Keynes seguía muy de cerca la evolución de la coyuntura americana, con lo que, desde su inicio, tenía un conocimiento de primera mano de las características esenciales de la economía y de los mercados en los que se produce la conmoción. La difusión de los efectos de la perturbación afectaría seriamente a su país, que era el prototipo de economía abierta al exterior, y sobrevino en un momento vital del economista inglés de gran vigor intelectual y con la suficiente madurez e inquietud para que el cataclismo constituyera el detonante que pusiera a pleno rendimiento su talento.

Skidelsky destaca muy bien el revulsivo que supuso la Gran Depresión en el pensamiento de Keynes ${ }^{14}$. No se trataba ya de una economía esclerótica en la que las rigideces dificultaban los ajustes, sino de una economía flexible y en expansión. Esta circunstancia le hizo meditar sobre las condiciones de las economías modernas, y el acento pasó de la dificultad de ajuste a la incertidumbre. Para Skidelsky, «la generalidad y profundidad de la depresión deterioraron la fe de Keynes, que nunca había sido muy robusta, en los dos mecanismos "clásicos" de ajuste, salarios y tipo de interés».

La Teoría General es un manifiesto de rebeldía ante la incapacidad de la economía clásica para explicar una conmoción tan terrible. El biógrafo acentúa la trascendencia de la incertidumbre en la Teoría General y en los escritos posteriores de $1937^{15}$ : «La teoría de Keynes intenta explicar dos cosa: cómo las expectativas de ventas rentables pueden colapsar, provocando desempleo masivo; y porque una vez colapsada la demanda, no puede confiarse en que fuerzas automáticas conduzcan a la posición original».

En línea con su propia interpretación de la obra de Keynes, el biógrafo considera clave el capítulo 12 de la Teoría General: «es el más conectado con la propia vida de Keynes: el capítulo en el cual su autobiografía confluye con la economía. Su deuda intelectual con sus primeros trabajos sobre

${ }^{14}$ Sin olvidar los quebrantos en su faceta de inversor y gestor de patrimonios.

${ }_{15}$ Muy especialmente The General Theory of Employment (XIV, pp. 109-123) dedicado a responder a sus críticos. 
probabilidad es obvia...». Comparto la idea de que el capítulo 12 de la Teoria General recoge las inquietudes más profundas de Keynes respecto a la inestabilidad potencial de carácter financiero. Seguramente son las páginas más agudas que se han escrito sobre la psicología de los mercados de acciones, en las cuales una inteligencia privilegiada vuelca sus ideas bien acuñadas por muchos años de observación y reflexión. Dicho lo anterior, a mi juicio ese capítulo es el menos general del libro, puesto que refleja la realidad de los mercados anglosajones y, aún más, la de Estados Unidos. Resulta claro que Keynes basa sus consideraciones en un modelo de sistema financiero que descansa básicamente sobre los mercados de valores, esto es, sobre la elección directa por los inversores del activo financiero más conforme a sus necesidades e intereses. En Alemania o en Francia, el peso de las bolsas era comparativamente menor, y mayor el de la intermediación bancaria, y eran escasamente aplicables sus reflexiones al respecto.

\section{AL SERVICIO DE SU PAÍS}

El tercer volumen de la trilogía de Skidelsky se sitúa en un plano algo diferente al de los dos primeros. Esto es lógico, puesto que los últimos nueve años de la vida de Keynes están marcados por la determinación de un hombre enfermo que decide poner al servicio de su país en guerra, unas energías que se agotaban con rapidez. En dos ocasiones recoge Skidelsky el homenaje de Robbins en la carta que escribe a la viuda de Keynes, con motivo de su muerte: «Maynard ha dado su vida por su país, tanto como si hubiera caído en el campo de batalla».

En esta etapa, la mente de Keynes había dejado atrás buena parte del vigor creador como economista, pero sus convicciones las aplicó con talento en una situación de emergencia, con la conciencia de que estaba participando, representando a su país, en la planificación del futuro. Advierte Skidelsky sobre su propio instinto de historiador que le lleva a situar el debate económico en su entorno histórico y político. Siendo esto así, en el tercer tomo remarca esa orientación: «Este libro es, por tanto, una historia de la Segunda Guerra Mundial, desde un particular punto de vista, así como una historia de los proyectos financieros e intelectuales de Keynes». Desde la perspectiva de un economista profesional, que es la mía, el segundo volumen es el más sugestivo e inspirador, puesto que aborda de manera magistral el proceso de formación de las ideas de Keynes. El 
volumen tercero es, sin embargo, el más emocionante, y muestra la grandeza de un hombre extraordinario que se sacrifica por su país.

El año siguiente a la publicación de la Teoría General fue aciago para Keynes. Se produjo una baja muy pronunciada en la bolsa y perdió los dos tercios de su fortuna, lo cual le produjo un estado de tensión y ansiedad que agravó la dolencia cardíaca, que le mantendría en precarias condiciones. Poco después de responder a las primeras críticas a la Teoria General, con Keynes que no podía trabajar al ritmo acostumbrado, tienen lugar los preparativos bélicos de la Segunda Guerra Mundial. Keynes se plantea las fórmulas para financiar la guerra. Skidelsky pone énfasis en señalar dos aspectos en la aportación de Keynes: el primero, que aplica el análisis de la Teoría General; el segundo, que su propuesta defiende la capacidad de elección de los consumidores y el funcionamiento de los precios y mercados, en vez de orientarse hacia mecanismos intervencionistas que se ampararían con más facilidad en una situación tal de emergencia. La financiación del esfuerzo bélico no exigía, según el planteamiento de la Teoría General, la elevación del tipo de interés, puesto que éste no es el precio que equilibra el ahorro y la inversión. El ahorro se incrementaría con la renta, y un programa de rearme que elevara la renta nacional generaría el ahorro para financiarlo sin tener que subir el tipo de interés. Skidelsky pone especial cuidado en señalar la opción liberal de Keynes, que rechaza el mecanismo inflacionista y el racionamiento como fórmula para reducir el nivel de consumo de la población. Su esquema de ahorro forzoso y de preservar la capacidad de elección podría sorprender a los que encuadran a Keynes en el campo intervencionista ${ }^{16}$.

El centro del tercer libro de Skidelsky es, no obstante, la participación de Keynes en la delegación inglesa que negocia en los Estados Unidos el apoyo financiero de este país al Reino Unido, que había agotado sus recursos por sostener el conflicto en solitario, así como el diseño de las instituciones económicas responsables del orden internacional de la posguerra. Conviene precisar la peculiar participación de Keynes, que había estado ofreciendo sus servicios al Tesoro, el cual finalmente aceptó su colaboración en agosto de 1940. Era un asesor sin remuneración y sin cargo definido. Entre esa fecha y su muerte, en 1946, mantuvo una posición anómala de consejero a tiempo parcial del Ministro de Hacienda. El biógrafo nos recuerda que esta posición descansaba en un patrimonio que le permitía la independencia económica, y-su protagonismo se basaba en su personalidad, en su prestigio como economista, y en su autoridad moral.

16 «Paying for the War», The Times, 14 y 15 de noviembre de 1939 (XXII, pp. 41-51). 
En relación a la autoridad moral, el biógrafo argumenta que se fundamentaba en dos episodios claves. El primero fue la dimisión del Tesoro en 1919 para denunciar el tratado de paz, y el segundo, en la Teoría General. En ambas ocasiones eligió el camino difícil e impopular de manifestar su opinión con toda crudeza; en los dos momentos, algunos le aconsejaron que rebajara el tono del ataque, teniendo en cuenta la realidad política: «Decir la verdad de manera implacable era lo primero, después el compromiso entre verdad y política. Este fue el credo de Keynes y, en conjunto, cumplió con él». Seguramente, podría añadirse un tercer momento decisivo en el que mostró su talento y determinación: la crítica al retorno al patrón oro del Reino Unido con la paridad de preguerra, alzando su voz en contra del criterio de las principales instituciones.

Las discusiones sobre la ayuda financiera de los Estados Unidos al Reino Unido y la creación del Fondo Monetario Internacional fueron intensas y agravaron su enfermedad, adelantando su muerte. Skidelsky describe con detalle el marco de las discusiones, los avances y retrocesos y, lo que me ha parecido más original e importante, las fuerzas, las convicciones profundas que animaban a los interlocutores. Frente al poder político y económico de los Estados Unidos, la inteligencia y la capacidad de convicción proporcionaban resultados limitados. Como la mayoría de los liberales ingleses, nos dice su biógrafo, Keynes sobreestimó el deseo de ayuda de los Estados Unidos, creyendo que la cuestión esencial era convencer al presidente, sin tener en cuenta la efectividad de la división de poderes de la política norteamericana.

Desde los Estados Unidos se contemplaba con respeto la entereza del Reino Unido en la guerra, pero se consideraba también que era una oportunidad para debilitar al imperio y acabar con el sistema de preferencias comerciales. Para la izquierda norteamericana, Inglaterra era un poder imperial, y Londres, el centro del capitalismo de los banqueros en contra del cual se había alzado el New Deal: «Keynes no pudo entender nunca que los intereses de los británicos y de los norteamericanos no eran idénticos y atribuía las diferencias a las deficiencias del sistema político americano, confiando en exceso en la lógica y en la elocuencia para superarlos». Pero frente a la realidad del poder y a una visión completamente distinta del orden deseable de la posguerra, la capacidad de convicción de Keynes y el armazón teórico no constituía un bagaje suficiente. El ala izquierda del New Deal prefería la alianza con la progresista Unión Soviética que con el reaccionario imperio inglés. Documenta Skidelsky las simpatías comunistas de White. Los argumentos técnicos y la imaginación de Keynes 
se estrellaban en el muro del poder con ideas e intereses muy distintos: «Keynes dio a los Acuerdos de Bretton Woods su distinción, no su sustancia... El Acuerdo no estaba modelado por la Teoría General, sino por el deseo de los Estados Unidos de incorporar un patrón oro actualizado como medio de liberalizar el comercio. Si hubo más ideología subterránea, fue la determinación de Morgenthau de concentrar el poder en Washington».

Con todas estas limitaciones, el papel de Keynes fue extraordinariamente importante, actuando, de hecho, como el miembro más destacado de la delegación británica. En un discurso en la Casa de Lores ${ }^{17}$, Keynes señalaba que en las negociaciones estaba manteniendo los tres principios por los que había luchado los últimos veinte años: «Estamos decididos a que, en el futuro, el valor externo de la esterlina sea conforme con el valor interno como resultado de nuestra política doméstica, y no al revés. Segundo, intentamos retener el control de nuestra tasa de interés, de forma que podamos mantenerla tan baja como sea adecuada para nuestros propósitos, sin que interfieran los flujos y reflujos de los movimientos internacionales de capital o la huida del dinero caliente. Tercero, aunque intentamos prevenir la inflación, no aceptaremos la deflación impuesta por la influencia del exterior».

\section{NOTA FINAL}

En varias ocasiones Keynes reclamaba en sus escritos la simpatía y complicidad del lector de literatura económica para que, dejando en un segundo plano las diferencias menores, no perdiera el hilo central de la argumentación. Eso era lo importante: el argumento esencial. El lector habrá podido comprobar que la obra de Keynes y la biografía de Skidelsky tienen mi simpatía y complicidad, lo cual no significa, como se ha puesto de relieve, tanto en este trabajo como en mi libro sobre Keynes, que no critique determinados aspectos concretos. Me considero un economista profesional y no puedo evitar la lectura de la trilogía de Skidelsky desde el ángulo predominante econórnico. En ese sentido, como ya he apuntado, el volumen segundo, The Economist as Saviour, me parece el más importante y sugerente, pero el primero y el tercero creo que son libros magníficos que explican y complementan la personalidad y las aportaciones de Keynes.

${ }_{17}$ House of Lords Debates, 23 de mayo de 1944 (XXVI, p. 16). 
La obra de Skidelsky recoge, en mi opinión, la esencia del pensamiento de Keynes. El economista que emerge de la biografía tiene rasgos muy especiales y es producto de una serie de circunstancias difícilmente repetibles: «Como todos los genios fue un genio solitario [...] Cuando en los años setenta y ochenta se evocaba la necesidad de un "nuevo Keynes", lo que se estaba reclamando era la repetición de un fenómeno que ha ocurrido muy raramente en la historia».

Keynes era profundamente antimarxista, pero simpatizaba con algunos aspectos del credo laborista. No era opuesto al capitalismo definido como sistema de empresa y propiedad privada, pero no consideraba viable el laisse-faire. Intentó redefinir el papel del Estado en la sociedad moderna para evitar los desórdenes económicos haciéndolo compatible con los valores liberales tradicionales. Fue el último de los grandes Liberales Ingleses. Fue esencialmente un economista inglés. Sus conocimientos de los mercados internacionales, de la situación de otros países y sus propuestas de regulación se filtraban por el prisma y los intereses del Reino Unido. Era un gran patriota, defensor de los modos de vida y de las tradiciones que juzgaba debían protegerse. Cuando en los años treinta expresó sin ambages estas ideas, recibió la felicitación del líder fascista inglés Oswald Mosley, que se congratuló por lo que entendía como una conversión. La respuesta de Keynes fue fulminante: «Escribo así no para unirme a usted, sino para salvar al país de usted».

Keynes revolucionó la manera de entender la economía y sus proposiciones podían parecer extremadas en ocasiones. El biógrafo suaviza ese perfil: «La verdad es que, tanto en su propia vida como en la economía, Keynes tensó las normas pero sin romperlas». Sin embargo, «ser revolucionario en el pensamiento pero cauteloso en la acción» ha tenido el problema de que con la muerte queda sólo el legado revolucionario sin la prudencia en la aplicación. Para los banqueros más conservadores era el «genio del mal que estaba detrás de la destrucción del patrón oro y del insensato experimento del New Deal».

Concebía Keynes la economía como una ciencia moral que ha de considerar los móviles de actuación, las expectativas y las incertidumbres psicológicas. Su crítica a Tinbergen ${ }^{18}$ se fundamenta en que éste considera el material estadístico como constante y homogéneo, lo cual anula la validez del modelo en el futuro. Decía a menudo que prefería tener razón de

${ }^{18}$ «Professor Tinbergen's Method», The Economic Joumal, septiembre de 1939 (XIV, pp. 306-318). 
forma imprecisa que estar equivocado de forma exacta, y se muestra despectivo sobre el enfoque del equilibrio general.

El biógrafo pone especial énfasis en situar el escepticismo de Keynes respecto al empleo de las matemáticas en economía, en relación a la visión ya expresada en el Treatise on Probability y con la imposibilidad de conocer el futuro: «El futuro nunca se parece al pasado, como es bien conocido» ${ }^{19}$. Ésa es la razón fundamental de su crítica a la economía clásica «que trata de afrontar el presente prescindiendo del hecho de que conocemos muy poco acerca del futuro». De ese desconocimiento del futuro procede su preferencia por la actuación a corto plazo, porque consideraba más racional intentar perseguir objetivos modestos con alta probabilidad de conseguirlos, que otros ambiciosos con poca probabilidad de lograrlos; por eso, apunta Skidelsky que no le gustaban las revoluciones y los cambios drásticos; de ahí también la tendencia de Keynes a considerar la estructura económica como dada: «El escepticismo de Keynes hacia los beneficios de cambios sociales en gran escala era igualado por su extraordinario optimismo acerca de la posibilidad de gestionar de forma inteligente los problemas a corto plazo».

Skidelsky acude a la biografía de Harrod para hacer referencia a la despedida de Keynes como editor del Economic Joumal, en febrero de 1945, en la cual éste brinda por «los economistas que son los garantes, no de la civilización, sino de la posibilidad de civilización». Continúa Harrod: «¿Cruzaron acaso por su mente las imágenes de Lytton, de Duncan, de Virginia? Ellos eran los garantes de la civilización. Los economistas tenían un papel más humilde, pero también indispensable: a éste había dedicado él su propia vida». La obra de Keynes es importante, sugestiva $\mathrm{y}$, sobre todo, analíticamente inspiradora; es fundamental su forma de enfocar los problemas y el ordenamiento de las opciones. La lectura de los escritos de Keynes es muy recomendable, y la magnífica biografía de Skidelsky permite perfilar las características del hombre, de la época y de su aportación a la economía.

\section{BIBLIOGRAFÍA}

Cunningham Wood, J. (ed.) (1983): Jobn Maynard Keynes. Critical Assessments, vol. I, Great Britain, Croom Helm.

19 «Some economic consecuences of a Declining Population», Eugenics Review, abril de 1937 (XIV, pp. 124-133). 
FELIX, D. (1999): Keynes. A critical Life, USA, Greenwood Press.

HARROD, R. F. (1951): La vida de Jobn Maynard Keynes [Primera edición en inglés]. Primera edición en español, México, Fondo de Cultura Económica, 1958, de donde se toman las referencias.

Hession, C. H. (1984): Jobn Maynard Keynes. A personal Biography of the men who Revolutioned Capitalism and the Way we Live, New York, Macmillan Publishing Company.

HiCKs, J. (1969): «Automatists, hawtreyans, and keynesians», Money, Credit and Banking, vol. I, núm. 3, agosto, pp. 307-317.

Keynes, M. (ed.) (1975): Essays on Jobn Maynard Keynes, Great Britain, Cambridge University Press.

MCCAnN, Jr. Ch. R. (1998): «Introduction», en Ch. R. MCCANn (ed.): Jobn Maynard Keynes. Critical Responses, vol. I, Great Britain, Routledge.

Mini, P. V. (1994): Jobn Maynard Keynes. A Study in the Psychology of Original Work, Great Britain, The Macmillan Press. LTD.

Moggridge, D. E. (1976): Keynes, 2. ${ }^{a}$ ed., Hong Kong, Macmillan Press Limited.

- (1992): Maynard Keynes. An Economist's Biography, London, Routledge.

SKIDELSKY, R. (2000): «Skidelsky on Keynes. Ideas and the world», The Economist, 25 de noviembre, pp. 109-112.

The COLleCted WRITINGS OF JOHN MAYNARD KEYNES, volúmenes citados: vol. VII (1973): The General Theory of Employment Interest and Money; vol. VIII (1973): A Treatise on Probability; vol. XIII (1973): The General Theory and After, Part I, Preparation; vol. XIV (1973): The General Theory and After, Part II, Defense and Development; vol. XV (1971): Activities 1906-1914. India and Cambridge; vol. XVI (1971): Activities 1914-1919. The Treasury and Versalles; vol. XXI (1982): Activities 1931-1939. World Crises and Policies in Britain and America; vol. XXII (1978): Activities 1939-1941. Internal War Finance; vol. XXVI (1980): Activities 1941-1946. Shaping the Post-War World. Employment and Commodities.

TORRERO, A. (1993): «R. Skidelsky. John Maynard Keynes. The Economist as Saviour 1920-1937, Revista de Economia Aplicada, núm. 2, vol. I, pp. 233-241.

- (1998): La obra de Jobn Maynard Keynes y su visión del mundo financiero, Madrid, Civitas. 